\title{
Right ventricular pacing is associated with increased rates of appropriate implantable cardioverter defibrillator shocks
}

\author{
Liane A. Arcinas ${ }^{1}$ (D) | William F. Mclntyre ${ }^{2}$ | Ashraf Farag ${ }^{1}$ | Dominique Kushneriuk ${ }^{3}$ | \\ Brett Hiebert $^{4}$ | Colette M. Seifer ${ }^{4}$
}

${ }^{1}$ Department of Internal Medicine, Rady Faculty of Health Sciences, University of Manitoba, Winnipeg, Manitoba, Canada

${ }^{2}$ Population Health Research Institute, McMaster University, Hamilton, Ontario, Canada

${ }^{3}$ Section of Cardiology, University of Saskatchewan, Saskatoon, Saskatchewan, Canada

${ }^{4}$ Section of Cardiology, Rady Faculty of Health Sciences, University of Manitoba, Winnipeg, Manitoba, Canada

\section{Correspondence}

Liane A. Arcinas, Department of Internal Medicine, Rady Faculty of Health Sciences, University of Manitoba, Winnipeg, Manitoba, Canada.

Email: umarcina@myumanitoba.ca

\begin{abstract}
Background: Right ventricular (RV) pacing has been associated with increased risk of pacemaker-induced cardiomyopathy, hospitalization and death among patients with implantable cardioverter defibrillators (ICDs). Little is known about its association with ventricular tachyarrhythmias. We hypothesize that $R V$ pacing is associated with increased incidence of appropriate ICD shocks and death.

Methods: Retrospective study of consecutive patients with de novo ICD insertion (excluding cardiac resynchronization therapy devices) from a single tertiary care center. Patients were classified into $<10 \%$ RV pacing (low-pace group) and $\geq 10 \%$ RV pacing (high-pace group). Data were compared using two-tailed $t$ tests and Fisher's exact test. Binomial logistic regression was performed to identify predictors of appropriate ICD therapies.

Results: A total of 178 patients (54 high paced and 124 low paced) were included. Mean follow-up was $43 \pm 11$ months. Appropriate shocks occurred in 27 patients (15\%) and were significantly higher in the high-pace group (35\% vs. $10 \%, p=0.008$ ), as the number of deaths ( $31 \%$ vs. $11 \%, p=0.001$ ). Binary logistic regression showed a significantly increased risk of shock (OR 2.99, $p=0.01$ ) and death (OR 3.61, $p=0.002$ ) in high-paced patients. Multivariable analysis showed no difference in risk of shocks based on age, sex or ejection fraction. Older patients had higher risk of death.

Conclusions: In this population of ICD patients, those with a high prevalence of RV pacing experienced more shocks for VF/VT and had higher mortality. Further studies should be done to determine whether minimizing RV pacing reduces arrhythmias, shock burden and death in patients with ICDs.
\end{abstract}

\section{1 | INTRODUCTION}

Multiple studies have shown an association between the burden of right ventricular (RV) pacing and adverse outcomes, including heart failure, hospitalization and death (Chan et al., 2011; Curtis et al., 2013; Kachboura et al., 2008; Wilkoff et al., 2002). Implantable cardioverter defibrillator (ICD) patients with both normal and reduced ejection fraction (EF) are subject to RV pacing-induced cardiomyopathy, with a reported incidence of 3\%-15\% (Chan et al., 2011; Dreger, Maethner, Bondke, Baumann, \& Melzer, 2012; Toff, Camm, \& Skehan, 2005). Proposed mechanisms for increased heart failure in this group include ventricular dyssynchrony and altered mechanical stress vectors that lead to cardiac dysfunction (Dreger et al., 2012; Lee et al., 2004; Sweeney et al., 2003).

While RV pacing's association with cardiomyopathy, hospitalizations and death is well established, the data on RV pacing-induced 


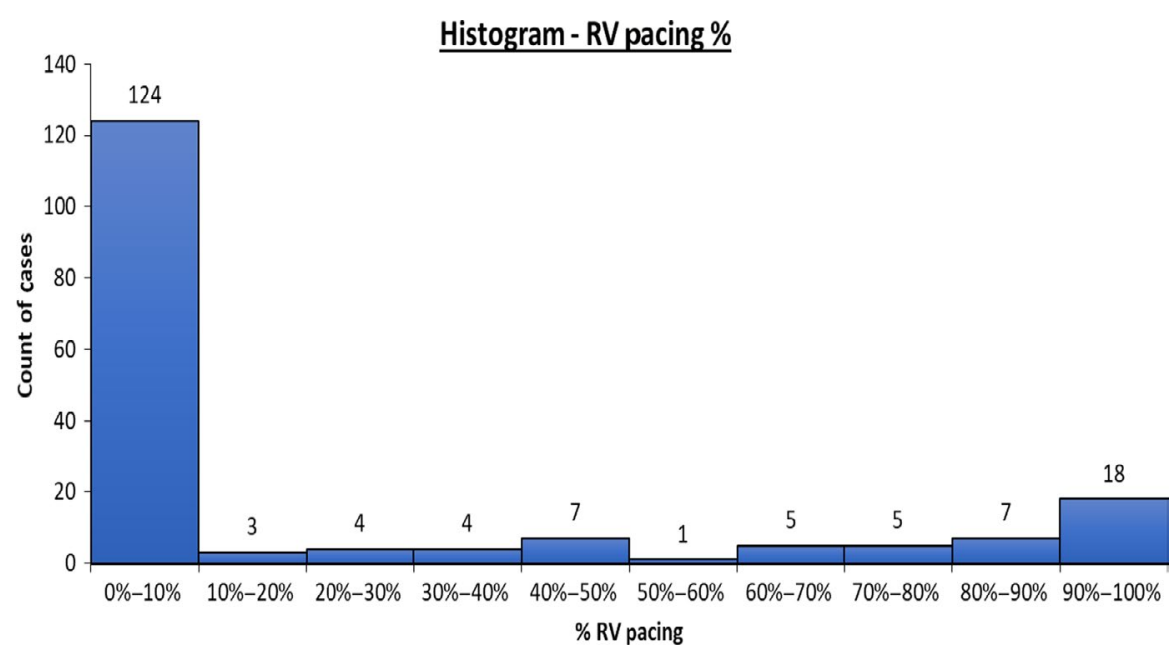

FIGURE 1 Distribution of study population based on rate of right ventricular pacing. RV Pacing \%: Right ventricular pacing percentage for participants; Count of cases: Number of participants in a particular right ventricular pacing percentage interval

ventricular arrhythmias are sparse (Cronin, Jones, Seth, \& Varma, 2017). A recent study showed that increasing RV pacing percentage is associated with a trend toward increased appropriate ICD shocks (Cronin et al., 2017).

We hypothesize that in patients with de novo ICD insertions, high RV pacing percentage ( $\geq 10 \%$ ) will be significantly associated with an increased number of appropriate ICD shocks due to ventricular tachycardia or ventricular fibrillation (VT/VF).

\section{2 | METHODS}

\section{1 | Study design}

This study is a retrospective single tertiary care center analysis of patients with a de novo ICD insertion between January 2007 and December 2010. Cardiac resynchronization devices and device replacements were excluded. Baseline clinical characteristics were recorded. Patient charts were reviewed, and the prevalence of RV pacing and the incidence of appropriate ICD therapies were collected. Majority of patients in this cohort had RV pacing rates of $<10 \%$ (Figure 1). Thus, patients were divided into two groups based on the prevalence of pacing: $<10 \% \mathrm{RV}$ pacing (low-pace group) and $\geq 10 \% \mathrm{RV}$ pacing (high-pace group).

\section{2 | Statistical analysis}

Data were compared using two-tailed $t$ tests and Fisher's exact test. Binary logistic regression was performed to identify predictors of appropriate ICD shocks and of death.

\section{3 | RESULTS}

\section{1 | Study population}

Among the 178 included patients, 54 were in the high-pace group and 124 were in the low-pace group. Demographics and clinical data for both groups are shown in Table 1. There was no statistical difference between the groups aside from the expected prevalence of
TAB LE 1 Baseline characteristics of participants divided according to high or low prevalence of right ventricular pacing

\begin{tabular}{|llll|}
\hline Baseline characteristics & $\begin{array}{l}\text { Low pace } \\
n=124\end{array}$ & $\begin{array}{l}\text { High pace } \\
n=54\end{array}$ & $p$-Value \\
\hline $\begin{array}{l}\text { Prevalence of pacing } \\
\text { (mean, \% } \pm \text { SD) }\end{array}$ & $0.9 \pm 1$ & $67 \pm 28$ & $<0.0001$ \\
\hline Age (mean, years) & $61 \pm 12$ & $69 \pm 11$ & $<0.0001$ \\
\hline Male (\%) & 81 & 83 & 0.7 \\
\hline $\begin{array}{l}\text { Ischemic CM (\%) } \\
\text { Primary prevention (\%) }\end{array}$ & 60 & 63 & 0.2 \\
\hline $\begin{array}{l}\text { Ejection fraction (mean, } \\
\% \pm \text { SD) }\end{array}$ & $30 \pm 11$ & $31 \pm 15$ & 0.7 \\
\hline $\begin{array}{l}\text { Ventricular pacing } \\
\text { minimization } \\
\text { programming }\end{array}$ & 32 & 0 & $n / a$ \\
\hline \begin{tabular}{l} 
Death from all causes (\%) \\
\hline
\end{tabular} & $11 \%$ & $31 \%$ & 0.001 \\
\hline
\end{tabular}

Note. CM: cardiomyopathy; n/a: not applicable; SD: standard deviation.

pacing and age (both $p<0.0001$ ). At baseline the mean LVEF was $30 \%$. The etiology of systolic dysfunction was ischemic in $72 \%$ of the low-pace group and $63 \%$ in the high-pace group. The mean follow-up for all patients was $43 \pm 11$ months.

\section{2 | ICD shocks}

Of the 178 patients in the study, appropriate shocks occurred in 27 patients (15\%). The proportion of patients in the high-pace group that received an appropriate shock was significantly higher than that in the low-pace group (35\% vs. $10 \%, p=0.008$ ). Univariable analysis showed a significantly increased risk of ICD shock in the high-pace group. This difference was maintained in multivariable analyses across subgroups, including age, sex and ejection fraction (Table 2).

\section{3 | Mortality}

The proportion of patients who died was significantly higher in the high-pace versus low-pace group (Table 1, 31\% vs. $11 \%$; $p=0.001$ ). 
TAB LE 2 Incidence of appropriate implantable cardioverter defibrillator (ICD) shocks in patients with a high and low prevalence of right ventricular pacing. Binary logistic regression analysis (univariable and multivariable) of different possible predictors of ICD shock and/or death

\begin{tabular}{|c|c|c|c|c|c|c|c|}
\hline & & \multicolumn{2}{|l|}{$\begin{array}{l}\text { Low pace } \\
n=124\end{array}$} & \multicolumn{2}{|l|}{$\begin{array}{l}\text { High pace } \\
n=54\end{array}$} & \multicolumn{2}{|l|}{$p$-Value } \\
\hline \multicolumn{2}{|c|}{$\begin{array}{l}\text { Patients who received ICD shock } \\
\text { (Number, \%) }\end{array}$} & \multicolumn{2}{|l|}{$13(10 \%)$} & \multicolumn{2}{|l|}{$14(35 \%)$} & \multicolumn{2}{|l|}{0.008} \\
\hline \multicolumn{4}{|c|}{$\begin{array}{l}\text { Univariable analysis } \\
\text { Outcome: ICD shock }\end{array}$} & \multicolumn{4}{|c|}{$\begin{array}{l}\text { Univariable analysis } \\
\text { Outcome: Death }\end{array}$} \\
\hline RV pacing $\geq 10 \%$ & 2.99 & $1.29-6.9$ & 0.01 & $\mathrm{RV}$ pacing $\geq 10 \%$ & 3.61 & $1.62-8.03$ & 0.002 \\
\hline \multicolumn{4}{|c|}{$\begin{array}{l}\text { Multivariable analysis } \\
\text { Outcome: ICD shock }\end{array}$} & \multicolumn{4}{|c|}{$\begin{array}{l}\text { Multivariable analysis } \\
\text { Outcome: Death }\end{array}$} \\
\hline Variable & OR & $95 \% \mathrm{Cl}$ & $p$-Value & Variable & OR & $95 \% \mathrm{Cl}$ & $p$-Value \\
\hline EF (per \%) & 0.98 & $0.94-1.02$ & 0.303 & EF (per \%) & 0.98 & $0.94-1.02$ & 0.41 \\
\hline
\end{tabular}

Note. $\mathrm{Cl}$ : confidence interval; EF: ejection fraction; OR: odds ratio; RV: right ventricular.

${ }^{a}$ Odds ratio and corresponding confidence interval for sex (male) are undefined as there were no women who died in this study population.

Multivariable analysis showed no increased risk of death based on sex or ejection fraction. As expected, age was associated with a significant risk of death, with older patients having higher mortality.

\section{DISCUSSION}

In our center's population of patients with first-time ICD implantation, a high rate of $\mathrm{RV}$ pacing $(\geq 10 \%)$ is associated with a significant increase in appropriate ICD shocks. As described previously, increased rates of RV pacing are associated with a reduction in left ventricular ejection fraction and symptomatic heart failure. It is plausible that pacing-induced cardiomyopathy acts as a substrate for increased ventricular arrhythmias and/or vice versa (Chan et al., 2011; Curtis et al., 2013; Kachboura et al., 2008; Wilkoff et al., 2002). Contrary to physiological ventricular activation, RV pacing can result in ventricular dyssynchrony (Cronin et al., 2017; Wilkoff et al., 2002). As observed in the recent study by Cronin et al. (2017), RV pacing had an increased trend to ventricular arrhythmias and ICD shocks, but this risk decreased when RV pacing was very low $(1 \%-5 \%)$ or very high ( $\geq 98 \%)$. This supports the likely mechanism of ventricular dyssynchrony from RV pacing and that preventing it by either minimizing pacing or by eliminating physiologic ventricular contraction via complete RV pacing may decrease ventricular arrhythmias and ICD shocks (Cronin et al., 2017).

Patients in the high RV pacing group also had significantly higher overall mortality rates, with the difference maintained across several subgroups including sex and EF. Although we hypothesize that this increased mortality is likely due to the deleterious effects of RV pacing, there was a significant difference in age between the groups with the high RV pacing group being significantly older which may have also contributed to this outcome.

To the best of our knowledge, our study is novel in demonstrating high rates of RV pacing ( $\geq 10 \%$ ) in ICD patients are significantly associated with increased appropriate ICD shocks and mortality. Minimizing RV pacing in ICD patients may help decrease ventricular arrhythmias and appropriate ICD shocks. Further prospective studies are needed to support this finding.

The limitations of this study were that it was a single-center retrospective observational study and that patients' New York Heart Association (NYHA) class, quality of life, baseline rhythm, baseline QRS width and medical treatments were not assessed. Previous studies have shown that optimal medical therapy including beta-blockers and ACE-inhibitors reduces mortality in the high arrhythmia risk population (Kadish et al., 2004; The Antiarrhythmics versus Implantable Defibrillators (AVID) Investigators, 1997). Lastly, majority of our study population were in the low-pace group ( $<10 \%)$. Thus, we were unable to separately analyze patients who are very highly RV paced (such as those who were paced at $98 \%-100 \%$ of the time) as their numbers were very low in this population. As demonstrated by Cronin et al, significant differences in shock and mortality may be seen among patients who are very highly paced compared to those who are only minimally to moderately paced.

\section{5 | CONCLUSION}

In this population of ICD patients, a higher prevalence of RV pacing was associated with a higher incidence of appropriate shocks. 
Patients with a high prevalence of RV pacing $(\geq 10 \%)$ were older, experienced more appropriate shocks and died more often. Minimization of RV pacing may reduce arrhythmia, shock burden and prevent death in patients with ICDs who do not have an indication for pacing.

\section{CONFLICT OF INTEREST}

All authors have no conflicts of interest to declare.

\section{ORCID}

Liane A. Arcinas (iD https://orcid.org/0000-0001-8336-8377

\section{REFERENCES}

Chan, J. Y., Fang, F., Zhang, Q., Fung, J. W., Razali, O., Azlan, H., ... Yu, C. M. (2011). Biventricular pacing is superior to right ventricular pacing in bradycardia patients with preserved systolic function: 2-year results of the PACE trial. European Heart Journal, 32, 2533-2540. https://doi.org/10.1093/eurheartj/ehr336

Cronin, E. M., Jones, P., Seth, M. C., \& Varma, N. (2017). Right ventricular pacing increases risk of appropriate implantable cardioverterdefibrillator shocks asymmetrically: An analysis of the ALTITUDE database. Circulation Arrhythmia and Electrophysiology, 10, e004711. https://doi.org/10.1161/CIRCEP.116.004711

Curtis, A., Worley, S., Adamson, P., Chung, E. S., Niazi, I., Sherfesee, L., ... M., (2013). Biventricular pacing for atrioventricular block and systolic dysfunction. New England Journal of Medicine., 368, 1585-1593. https://doi.org/10.1056/NEJMoa1210356

Dreger, H., Maethner, K., Bondke, H., Baumann, G., \& Melzer, C. (2012). Pacing-induced cardiomyopathy in patients with right ventricular stimulation for $>15$ years. Europace, 14, 238-242.

Kachboura, S., Ben Halima, A., Fersi, I., Marrakchi, S., Zouaoui, W., \& Kammoun, I. (2008). Assessment of heart failure and left ventricular systolic dysfunction after cardiac pacing in patients with preserved left ventricular systolic function. Annales De Cardiologie Et D'angeiologie, 57, 29-36. https://doi.org/10.1016/j.ancard.2007.09.011
Kadish, A., Dyer, A., Daubert, J. P., Quigg, R., Estes, N. A., Anderson, K. P., ... Defibrillators in Non-Ischemic Cardiomyopathy Treatment Evaluation (DEFINITE) Investigators (2004). Prophylactic defibrillator implantation in patients with nonischemic dilated cardiomyopathy. The New England Journal of Medicine, 350, 2151-2158. https:// doi.org/10.1056/NEJMoa033088

Lee, M. A., Dae, M. W., Langberg, J. J., Griffin, J. C., Chin, M. C., Finkbeiner, W. E., ... Rosenqvist, M. (2004). Effects of long-term right ventricular apical pacing on left ventricular perfusion, innervation, function and histology. Journal of the American College of Cardiology, 24, 225-232. https://doi.org/10.1016/0735-1097(94)90567-3

Sweeney, M. O., Hellkamp, A. S., Ellenbogen, K. A., Greenspon, A. J., Freedman, R. A., Lee, K. L., \& Lamas, G. A. (2003). Adverse effect of ventricular pacing on heart failure and atrial fibrillation among patients with normal baseline QRS duration in a clinical trial of pacemaker therapy for sinus node dysfunction. Circulation, 103, 2932-2937.

The Antiarrhythmics versus Implantable Defibrillators (AVID) Investigators (1997). A comparison of antiarrhythmic-drug therapy with implantable defibrillators in patients resuscitated from nearfatal ventricular arrhythmias. The New England Journal of Medicine, 337, 1576-1583.

Toff, W. D., Camm, A. J., \& Skehan, J. D. (2005). Single-chamber versus dual-chamber pacing for high-grade atrioventricular block. New England Journal of Medicine, 353, 145-155. https://doi.org/10.1056/ NEJMoa042283

Wilkoff, B. L., Cook, J. R., Epstein, A. E., Greene, H. L., Hallstrom, A. P., Hsia, H., ... Sharma, A. (2002). Dual-chamber pacing or ventricular backup pacing in patients with an implantable defibrillator, the dual chamber and VVI implantable defibrillator (DAVID) trial. The Journal of the American Medical Association, 288(24), 3115-3123. https://doi. org/10.1001/jama.288.24.3115

How to cite this article: Arcinas LA, Mclntyre WF, Farag A, Kushneriuk D, Hiebert B, Seifer CM. Right ventricular pacing is associated with increased rates of appropriate implantable cardioverter defibrillator shocks. Ann Noninvasive Electrocardiol. 2019;24:e12636. https://doi.org/10.1111/anec.12636 